\title{
An Advanced Practice Provider Clinical Fellowship as a Pipeline to Staffing a Hospitalist Program
}

\author{
Christina Lackner, PA-C; Shaker Eid, MD, MBA; Tiffani Panek, MA; Flora Kisuule, MD, MPH*
}

Division of Hospital Medicine, Johns Hopkins Bayview Medical Center, Baltimore, Maryland.

BACKGROUND: Approximately $83 \%$ of hospitalist groups around the country utilize advanced practice providers; however, the demand for hospitalists continues to exceed the supply, and this has led to increased utilization of advanced practice providers in hospital medicine. Advanced practice providers receive very limited inpatient training, and there is wide variation in their clinical abilities after graduation.

OBJECTIVE: To determine if an advanced practice provider fellowship is a cost-effective pipeline for filling vacancies within a hospitalist program.

METHODS: In 2014, a one-year advanced practice providers clinical fellowship in hospital medicine was established. Working one-on-one with an experienced hospitalist faculty member, the fellows evaluate and manage patients. The program consists of $80 \%$ clinical experience, in the inpatient setting, and $20 \%$ didactic instruction. Up to four fellows are accepted each year and are eligible for hire, after training, if there are vacancies.

RESULTS: The duration of onboarding and cost to the division were significantly reduced after implementation of the program (25.4 vs 11.0 weeks, $P=.017$ and $\$ 361,714$ vs $\$ 66,000, P=.004$ ).

CONCLUSION: The advanced practice provider fellowship has proven beneficial for the hospitalist division by (1) reducing costs associated with having unfilled vacancies, (2) improving capacity on the hospitalist service, and (3) providing a pipeline for filling nurse practitioners (NP) and physician assistant (PA) vacancies on the hospitalist service. Journal of Hospital Medicine 2019;14:336-339. Published online first March 20, 2019. ( 2019 Society of Hospital Medicine

\section{T}

here is an increasing utilization of advanced practice providers (APPs) in the delivery of healthcare in the United States. ${ }^{1,2}$ As of 2016, there were 157,025 nurse practitioners (NPs) and 102,084 physician assistants

(PAs) with a projected growth rate of $6.8 \%$ and $4.3 \%$, respectively, which exceeds the physician growth rate of $1.1 \%{ }^{2}$ This increased growth rate has been attributed to the expectation that APPs can enhance the quality of physician care, relieve physician shortages, and reduce service costs, as APPs are less expensive to hire than physicians. ${ }^{3,4}$ Hospital medicine is the fastest growing medical field in the United States, and approximately $83 \%$ of hospitalist groups around the country utilize APPs; however, the demand for hospitalists continues to exceed the supply, and this has led to increased utilization of APPs in hospital medicine. . $^{5-10}$

APPs receive very limited inpatient training and there is wide variation in their clinical abilities after graduation. ${ }^{11}$ This is an issue that has become exacerbated in recent years by a change in the training process for PAs. Before 2005, PA programs were typically two to three years long and required the same prerequisite courses as medical schools. ${ }^{11}$ PA students

*Corresponding author: Flora Kisuule, MD, MPH; E-mail: fkisuul1@jhmi.edu; Telephone: 410-550-9856

Received: August 4, 2018; Revised: January 18, 2019;

Accepted: January 29, 2019

๑) 2019 Society of Hospital Medicine DOI 10.12788/jhm.3183 completed more than 2,000 hours of clinical rotations and then had to pass the Physician Assistant National Certifying Exam before they could practice. ${ }^{12}$ Traditionally, PA programs typically attracted students with prior healthcare experience. ${ }^{11}$ In 2005, PA programs began transitioning from bachelor's degrees to requiring a master's level degree for completion of the programs. This has shifted the demographics of the students matriculating to younger students with little-to-no prior healthcare experience; moreover, these fresh graduates lack exposure to hospital medicine. ${ }^{11}$

NPs usually gain clinical experience working as registered nurses (RNs) for two or more years prior to entry into the NP program. NP programs for baccalaureate-prepared RNs vary in length from two to three years. ${ }^{2}$ There is an acute care focus for NPs in training; however, there is no standardized training or licensure to ensure that hospital medicine competencies are met. ${ }^{13-15}$ Some studies have shown that a lack of structured support has been found to affect NP role transition negatively during the first year of practice, ${ }^{16}$ and graduating NPs have indicated that they needed more out of their clinical education in terms of content, clinical experience, and competency testing. ${ }^{17}$

Hiring new APP graduates as hospitalists requires a longer and more rigorous onboarding process. On-the-job training in hospital medicine for new APP graduates can take as long as six to 12 months in order for them to acquire the basic skill set necessary to adequately manage hospitalized patients..$^{15}$ This extended onboarding is costly because the APPs are receiving a full hospitalist salary, yet they are not functioning at full 
TABLE 1. Curriculum Highlights

\begin{tabular}{|c|c|}
\hline Time Period & Activities \\
\hline Day one & Administrative orientation \\
\hline During the first month & Fellows attend hospital medicine boot camp for five days \\
\hline First six to eight weeks & Clinical onboarding for the fellow. Paired with a physician. Patient cap slowly raised from baseline of 10 to 13. \\
\hline \multirow[t]{13}{*}{40 weeks } & - Fellows work alongside a physician caring for patients. The fellows assists with: \\
\hline & - being first call on all patients for nurse questions \\
\hline & - handing off patients \\
\hline & - writing patient notes \\
\hline & - discharges \\
\hline & - order entries \\
\hline & - calling and following up on consults \\
\hline & - arranging family meetings \\
\hline & - presenting at multi-D rounds \\
\hline & - admissions \\
\hline & - communicating with primary care doctors \\
\hline & - performing medication reconciliation \\
\hline & - The physician-fellow dyad sees three more patients \\
\hline Once a week & The fellow attends weekly didactics \\
\hline Once a month & The fellow receives training in procedures \\
\hline
\end{tabular}

capacity. Ideally, there should be an intermediary training step between graduation and employment as hospitalist APPs. Studies have shown that APPs are interested in formal postgraduate hospital medicine training, even if it means having a lower stipend during the first year after graduating from their NP or PA program. 9,15,18

The growing need for hospitalists, driven by residency workhour reform, increased age and complexity of patients, and the need to improve the quality of inpatient care while simultaneously reducing waste, has contributed to the increasing utilization of and need for highly qualified APPs in hospital medicine. ${ }^{11,19,20}$ We established a fellowship to train APPs. The goal of this study was to determine if an APP fellowship is a cost-effective pipeline for filling vacancies within a hospitalist program.

\section{METHODS}

\section{Design and Setting}

Johns Hopkins Bayview Medical Center (JHBMC) is a 440 bed hospital in Baltimore Maryland. The hospitalist group was started in 1996 with one physician seeing approximately 500 discharges a year. Over the last 20 years, the group has grown and is now its own division with 57 providers, including 42 physicians, 11 APPs, and four APP fellows. The hospitalist division manages $\sim 7,000$ discharges a year, which corresponds to approximately $60 \%$ of admissions to general medicine. Hospitalist APPs help staff general medicine by working alongside doctors and admitting patients during the day and night. The APPs also staff the pulmonary step down unit with a pulmonary attending and the chemical dependency unit with an internal medicine addiction specialist.

The growth of the division of hospital medicine at JHBMC is a result of increasing volumes and reduced residency duty hours.
The increasing full time equivalents (FTEs) resulted in a need for APPs; however, vacancies went unfilled for an average of 35 weeks due to the time it took to post open positions, interview applicants, and hire applicants through the credentialing process. Further, it took as long as 22 to 34 weeks for a new hire to work independently. The APP vacancies and onboarding resulted in increased costs to the division incurred by physician moonlighting to cover open shifts. The hourly physician moonlighting rate at JHBMC is $\$ 150$. All costs were calculated on the basis of a 40-hour work week. We performed a pre- and postanalysis of outcomes of interest between January 2009 and June 2018. This study was exempt from institutional review board review.

\section{Intervention}

In 2014, a one year APP clinical fellowship in hospital medicine was started. The fellows evaluate and manage patients working one-on-one with an experienced hospitalist faculty member. The program consists of $80 \%$ clinical experience in the inpatient setting and $20 \%$ didactic instruction (Table 1). Up to four fellows are accepted each year and are eligible for hire after training if vacancies exist. The program is cost neutral and was financed by downsizing, through attrition, two physician FTEs. Four APP fellows' salaries are the equivalent of two entry-level hospitalist physicians' salaries at JHBMC. The annual salary for an APP fellow is $\$ 69,000$.

Downsizing by two physician FTEs meant that one less doctor was scheduled every day. The patient load previously seen by that one doctor (10 patients) was absorbed by the MD-APP fellow dyads. Paired with a fellow, each physician sees a higher cap of 13 patients, and it takes six weeks for the fellows to ramp-up to this patient load. When the fellow first starts, the team sees 10 patients. Every two weeks, the pair's census increases by one patient 
TABLE 2. Baseline Characteristics and Outcomes of Newly Hired APPs before and after Implementation of the APP Clinical Fellowship Program in 2014

\begin{tabular}{|c|c|c|c|}
\hline Variables & $\begin{array}{c}\text { Before }(2009-2013) \\
\text { Nonfellow Hires } \\
n=7\end{array}$ & $\begin{array}{l}\text { After }(2014-2018) \\
\text { Fellow Hires } \\
n=12\end{array}$ & $P$ Value \\
\hline Female & 100.0 & 75.0 & .127 \\
\hline $\begin{array}{l}\text { Race } \\
\text { White }\end{array}$ & & & - \\
\hline \multirow[t]{2}{*}{ Other } & 42.8 & 0.0 & \\
\hline & 14.4 & 8.3 & \\
\hline Time from APP school graduation to hire, months & $10.5[4,20]$ & $3.9[3.4,6.4]$ & .069 \\
\hline Total time with group, months & $17.9 \pm 10.6$ & $18.3 \pm 13.0$ & .735 \\
\hline Duration of vacancy, weeks (a) & $34.9 \pm 12.6$ & 0 & - \\
\hline \multicolumn{4}{|c|}{ Data are percentage or mean \pm standard deviation or median [IQR] } \\
\hline Abbreviations: APP, Advanced Practice Provider: & & & \\
\hline
\end{tabular}

to the cap of 13. Collectively, the four APP fellow-MD dyads make it possible for four physicians to see an additional 12 patients. The two extra patients absorbed by the service per day results in a net increase in capacity of up to 730 patient encounters a year.

\section{Outcomes and Analysis}

Our main outcomes of interest were duration of onboarding and cost incurred by the division to (1) staff the service during a vacancy and (2) onboard new hires. Secondary outcomes included duration of vacancy and total time spent with the group. We collected basic demographic data on participants, including, age, gender, and race. Demographics and outcomes of interest were compared pre- (2009-2013) and post- (2014-2018) initiation of the APP clinical fellowship using the chi-square test, the $t$-test for normally distributed data, and the Wilcoxon rank-sum for nonnormally distributed data, as appropriate. The normality of the data distribution was tested using the Shapiro-Wilk W test. Two-tailed $P$ values less than .05 were considered to be statistically significant. Results were analyzed using Stata/MP version 13.0 (StataCorp Inc, College Station, Texas).

\section{RESULTS}

Twelve fellows have been recruited, and of these, 10 have graduated. Two chose to leave the program prior to completion. Of the 10 fellows that have graduated, six have been hired into our group, one was hired within our facility, and three were hired as hospitalists at other institutions. The median time from APP school graduation to hire was also not different between the two groups (10.5 vs 3.9 months, $P=$.069). In addition, the total time that the new APP hires spent with the group was nonstatistically significantly different between the two periods (17.9 vs 18.3 months, $P=.735)$. Both the mean duration of onboarding and the cost to the division were significantly reduced after implementation of the program (25.4 vs 11.0 weeks, $P=.017$ and $\$ 361,714$ vs $\$ 66,000, P=.004$; Table 2).

The yearly cost of an APP vacancy and onboarding is incurred by doctor moonlighting costs (at the rate of $\$ 150$ per hour) to cover open shifts. The mean duration of vacancies and onboarding each year was 34.9 and 25.4 weeks, respectively, before the fellowship. The yearly cost of onboarding, after the establishment of the fellowship, is a maximum of $\$ 66,000$, derived from physician moonlighting to cover the six-week rampup at the very beginning of the fellowship and the five weeks of orientation to the pulmonary and chemical dependency units after the fellowship (Table 3).

\section{DISCUSSION}

Our APP clinical fellowship in hospital medicine at JHBMC has produced several benefits. First, the fellowship has become a pipeline for filling APP vacancies within our division. We have been able to hire for four consecutive years from the fellowship. Second, the ready availability of high-functioning and efficient APP hospitalists has cut down on the onboarding time for our new APP hires. Many new APP graduates lack confidence in caring for complex hospitalized patients. Following our 12-month clinical fellowship, our matriculated fellows are able to practice at the top of their license immediately and confidently. Third, the reduced vacancy and shortened onboarding periods have reduced costs to the division. Fourth, the fellowship has created additional teaching avenues for the faculty. The medicine units at JHBMC are comprised of hospitalist and internal medicine residency services. The hospitalists spend the majority of their clinical time in direct patient care; however, they rotate on the residency service for two weeks out of the year. The majority of 
TABLE 3. Onboarding Time for Newly Hired Nonfellow and Fellow APPs

\begin{tabular}{lcc}
\hline Services for which APPs are trained & $\begin{array}{c}\text { Nonfellow APPs } \\
\text { Time (weeks) }\end{array}$ & $\begin{array}{c}\text { APP Fellows } \\
\text { Time (weeks) }\end{array}$ \\
\hline Orientation to CDU & 2 & 1 \\
\hline Orientation to PCU & 4 & 4 \\
\hline Orientation to General Medicine Unit & $4-12$ & N/A \\
\hline Gradual increase in patient volume to expected caps & $\mathbf{2 2 - 3 4}$ & $\mathbf{1 1}$ \\
\hline Total training time (weeks) & 4 \\
\hline
\end{tabular}

Abbreviation: APP, Advanced Practice Provider; CDU, Chemical Dependency Unit; PCU, Progressive Care Unit.

physicians welcome the chance to teach more, and partnering with an APP fellow provides that opportunity.

As we have developed and grown this program, the one great challenge has been what to do with graduating fellows when we cannot hire them. Fortunately, the market for highly qualified, well trained APPs is strong, and every one of the fellows that we could not hire within our group has been able to find a position either within our facility or outside our institution. To facilitate this process, program directors and recruiters are invited to meet with the fellows toward the end of their fellowship to share employment opportunities with them.

Our study has limitations. First, had the $\$ 276,000$ from the attrition of two physicians been used to hire nonfellow APPs under the old model, then the costs of the two models would have been similar, but this was simply not possible because the positions could not be filled. Second, this is a single-site experience, and our findings may not be generalizable, particularly those pertaining to remuneration. Third, our study was underpowered to detect small but important differences in characteristics of APPs, especially time from graduation to hire, before and after the implementation of our fellowship. Further research comparing various programs both in structure and outcomes-such as fellows' readiness for practice, costs, duration of vacancies, and provider satisfaction—are an important next step.

We have developed a pool of applicants within our division to fill vacancies left by turnover from senior NPs and PAs. This program has reduced costs and improved the joy of practice for both doctors and APPs. As the need for highly qualified NPs and PAs in hospital medicine continues to grow, we may see more APP fellowships in hospital medicine in the United States.

\section{Acknowledgments}

The authors thank the advanced practice providers who have helped us grow and refine our fellowship.

Disclosures: The authors have nothing to disclose

\section{References}

1. Martsoff G, Nguyen P, Freund D, Poghosyan L. What we know about postgraduate nurse practitioner residency and fellowship programs. J Nurse Pract. 2017;13(7):482-487. doi: 10.1016/j.nurpra.2017.05.013.
2. Auerbach D, Staiger D, Buerhaus P. Growing ranks of advanced practice clinicians-implications for the physician workforce. $N$ Engl J Med. 2018;378(25):2358-2360. doi: 10.1056/NEJMp1801869.

3. Laurant $M$, Harmsen $M$, Wollersheim $H$, Grol R, Faber M, Sibbald B. The impact of nonphysician clinicians: do they improve the quality and cost-effectiveness of health care services? Med Care Res Rev. 2009;66(6 Suppl):36S-89S. doi: 10.1177/1077558709346277.

4. Auerbach DI. Will the NP workforce grow in the future? New forecasts and implications for healthcare delivery. Med Care. 2012;50(7):606-610. doi: 10.1097/MLR.0b013e318249d6e7.

5. Kisuule F, Howell E. Hospital medicine beyond the United States. Int J Gen Med. 2018;11:65-71. doi: 10.2147/IJGM.S151275.

6. Wachter RM, Goldman L. Zero to $50,000-T h e 20^{\text {th }}$ anniversary of the hospitalist. N Engl J Med. 2016;375(11):1009-1011. doi: 10.1056/NEJMp1607958.

7. Conrad, $\mathrm{K}$ and Valovska T. The current state of hospital medicine: trends in compensation, practice patterns, advanced practice providers, malpractice, and career satisfaction. In: Conrad K, ed. Clinical Approaches to Hospital Medicine. Cham, Springer; 2017:259-270.

8. Bryant SE. Filling the gaps: preparing nurse practitioners for hospitalist practice. J Am Assoc Nurse Pract. 2018;30(1):4-9. doi: 10.1097/ JXX.0000000000000008.

9. Sharma P, Brooks M, Roomiany P, Verma L, Criscione-Schreiber, L. Physician assistant student training for the inpatient setting: a needs assessment. J Physician Assist Educ. 2017;28(4):189-195. doi: 10.1097/JPA.0000000000000174.

10. Society of Hospital Medicine. 2016 State of Hospital Medicine Report. Available at: https://www.hospitalmedicine.org/about/press-releases/shm-releases-2016-state-of-hospital-medicine-report/. Accessed July 17, 2018.

11. Will KK, Budavari Al, Wilkens JA, Mishari K, Hartsell ZC. A Hospitalist postgraduate training program for physician assistants. J Hosp Med. 2010;5(2):948. doi: 10.1002/jhm.619.

12. Naqvi, S. Is it time for Physician Assistant (PA)/Nurse Practitioner (NP) Hospital Medicine Residency Training. Available at: http://medicine2.missouri.e., du/jahm/wp-content/uploads/2017/03/Is-it-time-for-PANP-Hospital-Medicine-Residency-Training-Final.pdf. Accessed July 17, 2018.

13. Scheurer D, Cardin T. The Role of NPs and PAs in Hospital Medicine Programs. From July, 2017 The Hospitalist. Available at: https://www.the-hospitalist.org/hospitalist/article/142565/leadership-training/role-nps-and-pashospital-medicine-programs. Accessed July 17, 2018.

14. Furfari K, Rosenthal L, Tad-y D, Wolfe B, Glasheen J. Nurse practitioners as inpatinet providers: a hospital medicine fellowship program. J Nurse Pract. 2014;10(6):425-429. doi: 10.1016/j.nurpra.2014.03.022.

15. Taylor D, Broyhill B, Burris A, Wilcox M. A strategic approach for developing an advanced practice workforce: from postgraduate transition-to-practice fellowship programs and beyond. Nurs Adm Q. 2017;41(1):11-19. doi: 10.1097/NAQ.0000000000000198.

16. Barnes $\mathrm{H}$. Exploring the factors that influence nurse practitioners role transition. J Nurse Pract. 2015;11(2):178-183. doi: 10.1016/j.nurpra.2014.11.004.

17. Hart MA, Macnee LC. How well are nurse practitioners prepared for practice: results of a 2004 questionnaire study. J Am Acad Nurse Pract. 2007;19(1):3542. doi: 10.1111/j.1745-7599.2006.00191.x

18. Torok H, Lackner C, Landis R, Wright S. Learning needs of physician assistants working in hospital medicine. J Hosp Med. 2012;7(3):190-194. doi: 10.1002/jhm.1001.

19. Kisuule F, Howell E. Hospitalists and their impact on quality, patient safety, and satisfaction. Obstet Gynecol Clin N Am. 2015;42(3):433-446. doi: 10.1016/j.ogc.2015.05.003.

20. Ford, W, Britting L. Nonphysician Providers in the hospitalist model: a prescription for change and a warning about unintended side effects. $J$ Hosp Med. 2010;5(2):99-102. doi: 10.1002/jhm.556. 